\title{
Colonic capacitance and transit in man: modulation by luminal contents and drugs
}

\author{
P S Kamath, S F Phillips, M K O’Connor, M L Brown, A R Zinsmeister
}

\begin{abstract}
We have examined whether the human colon is able to adapt its capacity to receive fluid, specifically, whether the caecum and ascending colon ('right colon') exhibited any reservoir function. Healthy volunteers had the caecum intubated from above with a device that permitted intraluminal pressures to be recorded while fluids were instilled into the caecum. Perfusates contained ${ }^{9{ }^{m}} T_{c}$-DTPA (diethylenetriamine pentaacetic acid) and volumes of the right colon were determined by two plane scintigraphy using gamma cameras. Different individuals received caecal infusions of 154 $\mathrm{mM} \mathrm{NaCl}$ (saline), an emulsion of oleic acid (with bile acids and lecithin) or a $100 \mathrm{mM}$ solution of mixed short chain fatty acids. Each person was pretreated by intravenous saline (placebo), morphine sulphate $(100 \mu \mathrm{g} / \mathrm{kg})$ or naloxone $(5.5 \mathrm{mg}$ as a bolus, followed by $10 \mu \mathrm{g} /$ $\mathrm{kg} / \mathrm{min}$ ). Volumes of the right colon were smallest during oleic acid infusion; morphine reversed the effect of luminal fat and allowed the colon to accommodate larger volumes. Transit from the right colon was more rapid for the emulsion of oleic acid than it was for saline or solutions of mixed short chain fatty acids. We conclude that the right colon may act as a reservoir and that this function can be modified by the nature of the contents and by pharmacological agents.
\end{abstract}

Though the proximal colon has been postulated to store digestive residues, ${ }^{12}$ the mechanisms whereby the aborad movement of contents might be slowed are unknown; indeed, it is uncertain how much storage actually occurs. These issues have been approached by correlating patterns of colonic contraction with the movements of contents in animals ${ }^{3}$ and man $^{46}$, using radiological imaging and intraluminal manometry. ${ }^{56}$ The methods used, however, were less than ideal; manometry was by radio telemetry capsules, ${ }^{5}$ the positions of which were uncertain, or by intraluminal catheters placed only in the distal colon. ${ }^{6}$ $x$ radiography exposes subjects to much radiation and must be used sparingly; moreover, barium labelled contents possibly move very differently from chyme.? Perfusion studies in man have suggested that diarrhoea can occur when the absorptive function of the proximal colon is surpassed; one of the factors determining colonic absorption is the quantity and quality of chyme delivered by the ileum. ${ }^{8}$ Finally, when oleic acid was infused into the human caecum, the scintigraphic dimensions of the proximal colon decreased, transit was accelerated and motility of the colon was abnormal. ${ }^{9}$

We wished to further examine whether the proximal colon of man was able to store chyme and whether we could modify the colon's response to intraluminal fatty acids by pharmacological means. Our hypothesis was that oleic acid would reduce the volume of the right colon (caecum and ascending colon) and accelerate transit, but that this response would be countered by an opiate. On the other hand, perfusion of the right colon with short chain fatty acids, normally the major organic anions of colonic fluid, ${ }^{10-12}$, might allow the colon to accept even larger volumes.

We found that the capacity of the right colon in man was least when the caecum was perfused with an emulsion of oleic acid; perfusion with isotonic saline or solutions of mixed short chain fatty acids allowed the colon to accommodate larger volumes, as did pretreatment with morphine sulphate. Thus, the human colon was able to expand and to accommodate a large volume of fluid or, under other circumstances, to reduce its capacitance. It seems likely that this phenomenon is of importance in modulating overall transit through the large intestine.

\section{Methods}

VOLUNTEERS

Twenty three studies were completed in 20 healthy subjects ( 14 men, 6 women), aged between 20 and 41 years; three men were used twice. None had a significant history of gastrointestinal disease, was on any medication or had abnormalities on physical examination. Women were studied in the first week of the menstrual cycle; in addition, they had negative pregnancy tests within 48 hours of the experiments. All gave written, informed consent of a protocol that was approved by the Radiation Control Committee and Institutional Review Board of Mayo Clinic.

INTUBATION

Subjects were intubated with a multilumen orocaecal tube with an outer diameter of $6 \mathrm{~mm}$. Perfused catheters (Dural Plastics, Dural, NSW, Australia) recorded motility from ports in the caecum (two), ileum (three) and jejunum (one). There were aspiration/infusion ports in the ileum and caecum. A radioopaque tube (Ferraris Engineering, Edmonton, London, UK) extended the length of the assembly, terminating at a mercury bag and balloon which, when inflated, facilitated passage of the assembly. ${ }^{13}$

MOTILITY RECORDINGS

Manometric catheters were constantly perfused at $0.1 \mathrm{ml} / \mathrm{min}$ with a low compliance, hydraulic 
capillary infusion system driven by a pressure head of nitrogen. The infusion system was connected to Statham Gould P23 pressure transducers (Statham Instruments Inc, Halto Rey, Puerto Rico) and the output displayed on a Honeywell 1600 (Honeywell Technical Instruments Inc, Denver, Co.) multichannel pen recorder with a chart speed of $25 \mathrm{~mm} / \mathrm{min}$. Amplified signals went to a PDP 11/23 computer for digitisation $(4 \mathrm{~Hz})$ and storage. Data were transferred to a VAX 750 computer through a DECNET communications channel for analysis of motility indices.

\section{TEST SOLUTIONS AND PHARMACOLOGICAL AGENTS}

The colonic infusate was either oleic acid, normal saline (154 $\mathrm{mM} \mathrm{NaCl}$ ) or a physiological mixture of short chain fatty acids. A $43 \mathrm{~g} / \mathrm{l}$ emulsion of oleic acid' was made up to simulate caecal concentrations of fat in moderate steatorrhoea. ${ }^{14}$ The solutions of mixed short chain fatty acids mixture was made up to a total concentration in the physiological range $(100 \mathrm{mM})$ and in appropriate ratios ${ }^{12}{ }^{15}$; these were, acetic $66 \%$, propionic $24 \%$ and butyric acids $10 \%$ (Mallinckrodt Inc, Paris, KY). Concentrations of the solutions of mixed short chain fatty acids were confirmed by gas liquid chromatography. ${ }^{16}$ The osmolality and $\mathrm{pH}$ of the oleic acid and solutions of mixed short chain fatty acids solutions were adjusted to $290 \mathrm{mOsmol} / \mathrm{kg}$ and $\mathrm{pH} 6.5$ with $\mathrm{NaCl}$ and $\mathrm{NaOH}$. All test solutions were labelled with $5 \mathrm{mCi}$ of ${ }^{99 \mathrm{~m}} \mathrm{~T}_{\mathrm{c}}$-DTPA.

Morphine sulphate (Wyeth Laboratories Inc, Philadelphia, PA) was given as a bolus of $100 \mu \mathrm{g} /$ kg. Naloxone (Narcan, Dupont Pharmaceuticals Inc, Manati, Puerto Rico) was given as a bolus of $5.5 \mathrm{mg}$ followed by an infusion at the rate of $10 \mu \mathrm{g} / \mathrm{kg} / \mathrm{min}$. Normal saline $(2 \mathrm{ml}$ ) was used as placebo for the pretreatments. All bolus doses of pharmacological agents were administered intravenously 30 minutes before the start of the colonic infusions.

\section{CONDUCT OF EXPERIMENTS (Fig 1)}

The tube was positioned on the morning before the day of this study and a series of tests was performed in the afternoon. These have been reported elsewhere. ${ }^{12}$ Subjects consumed a low

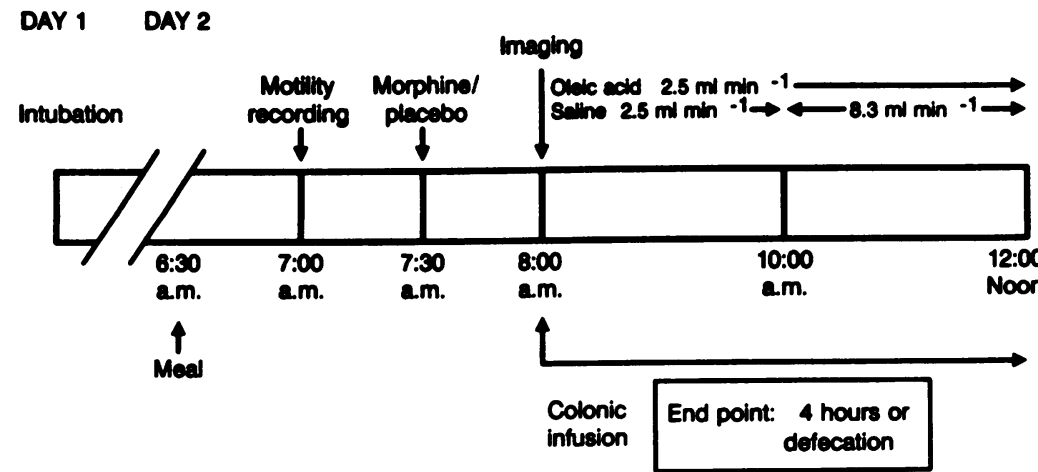

Figure 1: Study design showing times at which motility was recorded, pretreatment was administered and the colon was infused. In some experiments a solution of short chain fatty acid was used instead of oleic acid or saline (see text for details). residue $600 \mathrm{kcal}$ liquid supper $(50 \% \mathrm{CHO}, 15 \%$ protein and $35 \%$ fat) and the tube was left overnight in the ileocolonic region; its position was reconfirmed fluoroscopically next morning. At $630 \mathrm{am}$, a $385 \mathrm{kcal}$, liquid breakfast $(58 \%$ CHO, $26 \%$ protein, $14 \%$ fat) was taken and subjects were then asked to be recumbent for the remainder of the morning. Baseline postprandial recordings of motor activity were started, and 30 minutes before the colonic infusion, subjects were pretreated with either morphine, naloxone or placebo. Colonic infusion, imaging and recordings of motility were continued for four hours, or until subjects had an uncontrollable urge to defecate (Fig 1). Before removal of the tube, its position was rechecked fluoroscopically; minor aborad transit was observed occasionally but important orad movement was not observed.

The labelled oleic acid emulsion and solution of mixed short chain fatty acids solution were infused at a constant rate of $2.5 \mathrm{ml} / \mathrm{min}$, to mimic postprandial ileal flow. ${ }^{17}$ For the saline experiments, normal saline with isotope was infused at $2.5 \mathrm{ml} / \mathrm{min}$ for two hours; the rate of infusion was then increased to $8.3 \mathrm{ml} / \mathrm{min}$, to simulate ileal flow in diarrhoea. ${ }^{17} 18$ To facilitate expulsion of the isotope at the end of the experiment, 'cold' normal saline was infused at $8.3 \mathrm{ml} / \mathrm{min}$ ), or until the subjects defecated.

Subjects were randomised to three infusion groups, oleic acid (eight), solutions of mixed short chain fatty acids groups, (six) and saline (nine). Within the oleic acid and short chain fatty acids groups subjects were randomised to receive treatment with morphine sulfate or placebo; within the saline group they were randomised to receive morphine, naloxone or placebo (Table I).

\section{GAMMA CAMERA IMAGING}

For scintigraphy, two large field of view gamma cameras were used equipped with low energy all purpose collimators (Starcam, General Electric, Milwaukee). With modifications to the computer system, simultaneous dynamic acquisitions were performed with both cameras. The patient was positioned supine and images of the

TABLE I Study design: numbers of perfusates and pretreatments received by subjects

\begin{tabular}{llll}
\hline & \multicolumn{2}{l}{ Pretreatment } & \\
\cline { 2 - 4 } Colonic infusate & Placebo & Morphine & Naloxone \\
\hline Oleic acid & 4 & 4 & - \\
Saline & 3 & 3 & 3 \\
SCFA & $3+$ & $3 \dagger$ & - \\
\hline
\end{tabular}

*Mixture of short chain fatty acids; tone subject not analysed from this group for technical reasons (see text).

TABLE II Volume of right colon during caecal infusion of saline ${ }^{\star}$

\begin{tabular}{clc}
\hline $\begin{array}{c}\text { Effect of pretreatment with } \\
\text { Placebo }\end{array}$ & Morphine sulphate & Naloxone \\
\hline 210 & 223 & 185 \\
234 & 320 & 81 \\
210 & 174 & 175 \\
Mean 218 & 239 & 147 \\
\hline
\end{tabular}

* Median volume (in $\mathrm{ml}$ ) of the caecum and ascending colon during minutes 31-90 of infusion in nine subjects; each person received only one pretreatment. 

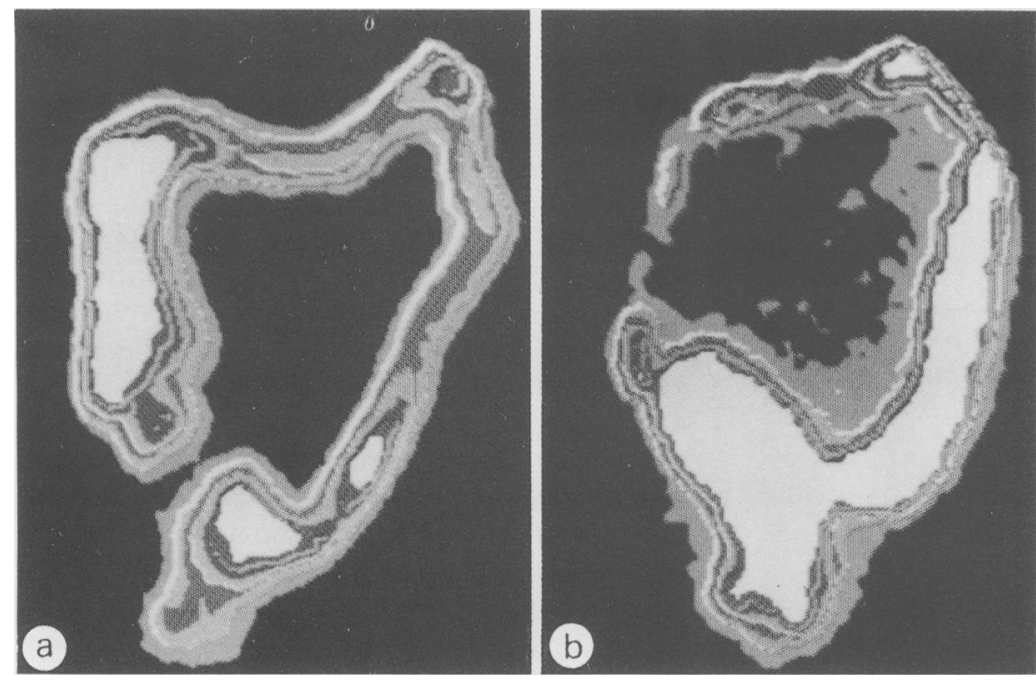

Figure 2: Scintiscans of colon during infusion of test solutions. (a) Obtained during infusion with saline (placebo pretreatment); it shows isotope filling the entire colon with the caecum and ascending colon being clearly outlined. The highest concentrations of counts (lightest shade) were recorded from the right colon and rectosigmoid region. (b) Obtained during infusion with oleic acid (placebo pretreatment); it shows little filling of the right colon and almost all counts are in the descending colon and beyond.

colon were obtained in the anterior and right lateral projections. Data were acquired into $64 \times 64$ matrices at $1 \mathrm{~min} /$ frame for up to four hours.

\section{ANALYSIS OF DATA}

\section{Volumes of the right colon}

The right colon was identified without difficulty (Fig 2). From its anterior and lateral images, the mean anterior diameter (a) and the mean lateral diameter (b) were obtained by profile analysis. ${ }^{19}$ Colonic dimensions were calculated from measurement of the full width of the colon at a half maximum of the profile of counts, taken horizontally through the right colon using a previously validated technique. ${ }^{19}$ In these preliminary experiments, phantoms were used to reconstruct the imaging technique. Among several analytical models evaluated, the one which most accurately reflected the true dimensions of the phantom was its full diameter measured at half the maximum number of counts recorded from the image. The length of the right colon $(\mathrm{L})$ was calculated from the anterior image by measuring its height in pixels and converting pixels to centimeters. The volume of the right colon was then calculated using the formula,

$$
\text { volume }=\prod \frac{\mathrm{a}}{2} \cdot \frac{\mathrm{b}}{2} \cdot \mathrm{L}
$$

In images where there was an overlap of sigmoid colon and caecum, the mean diameter of only that portion of the right colon that was clearly delineated was calculated.

\section{Transit}

Using a region of interest analysis, a time activity curve was generated of counts in the right colon, by drawing a box around it. The right colon was defined by the caecum, and ascending colon, up to the inflexion located in the upper right quadrant. The transverse colon extended from here to the inflexion in the upper left quadrant. Time activity curves were also generated of counts in the transverse and distal colon.

Counts were seen to reflux into the terminal ileum in most studies, the most important reflux occurred usually in the first 30 minutes and amounts of isotopes in the ileum remained relatively constant thereafter. Refluxed radioactivity was discounted from subsequent calculations of counts emptying from the right colon. As an index of how the proximal colon emptied itself of counts (that were being infused constantly), a right colonic 'emptying curve' was obtained by computing the 'proportionate counts in the right colon.' This was computed by dividing cumulative counts in the right colon by cumulative counts in the total colon at each scan. Emptying curves exhibited different shapes; some displayed sharp decreases in counts (Fig 3a). These 'mass movements' of isotope were easily identified and were defined quantitatively by a decrease of counts in the right colon of $\geq 20 \%$ over a three minute period. Other emptying curves (Figs 3b,c) showed smoother, more progressive decrements of counts.

Retention in and transit through the transverse colon was assessed by the cumulative counts in the transverse colon as a proportion of total counts passing beyond the right colon (and, therefore, entering the transverse or distal colons). This proportion was calculated for each scan and graphed together with proportionate scans in the distal colon (cauded to the transverse colon), again as a proportion of total counts beyond the right colon.

\section{Motility}

Records were first examined visually to two of the investigators. The major motility patterns we sought were large amplitude $(>60 \mathrm{mmHg})$, long duration ( $>12$ seconds) pressure waves in the colon; these were designated as colonic 'prolonged propagated contractions.' All pressure channels were also digitised and a computerised peak finding routine applied. For all contractions, the peak height, area and duration, and baseline were determined and a motility index calculated by the formula mobility index $=\log _{e}$ (\#peaks $\times$ sum of amplitudes +1 ).

\section{STATISTICAL ANALYSIS}

Those studies featuring oleic acid infusions had to be terminated between $90-120$ minutes because subjects had urges to defecate that were often uncontrollable. Because of this, volumes in the right colon only during the period between 31 minutes (when the right colon was filled) and 90 minutes could be used for comparison among treatments. The median volume of the scans between 31 and 90 minutes was first computed in each subject. The effects of perfusion group and pharmacologic agent were assessed comparing pairs of groups using the two-sample $t$ test. The log total colonic capacity up to the time of defecation, that is, the volume infused during the study period plus the volume of saline that 


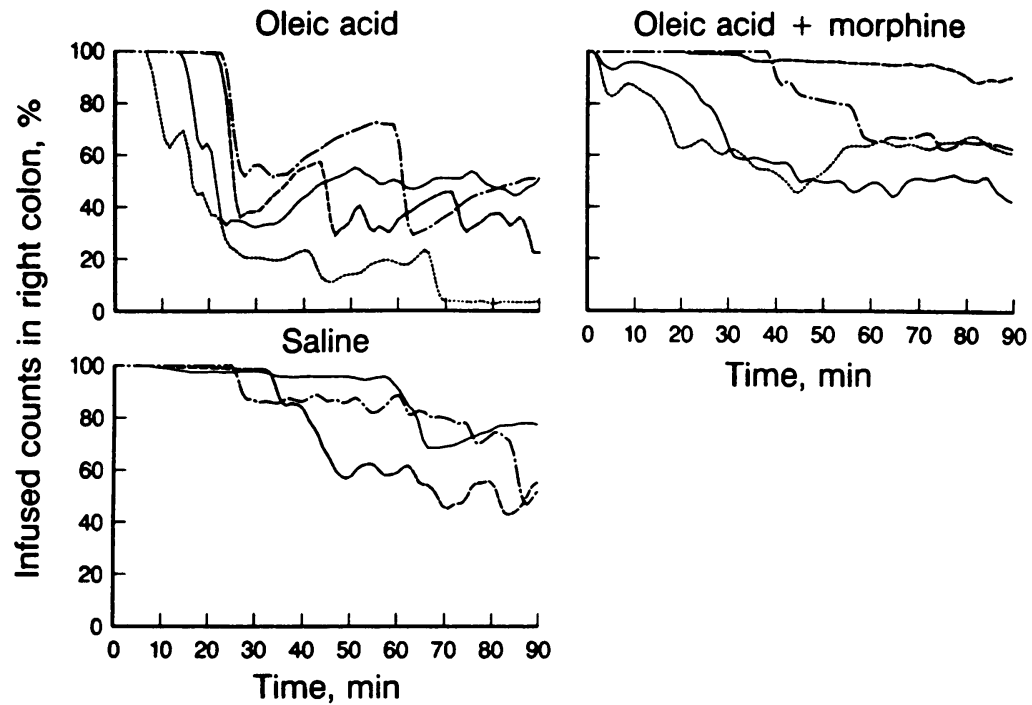

Figure 3: Three emptying curves of isotope from the right colon. The proportions of counts remaining in the right colon were plotted for the period 31-90 minutes of infusion. (a) Is from four persons perfused with oleic acid (placebo pretreatment); the emptying curves are interrupted by bolus movements of counts from the right colon. (b) Contrasts the effects of pretreatment with morphine, in four persons. Bolus transfers of isotope are much less prominent and emptying is more slowly progressive. (c) Shows results from three subjects infused with saline; the curves show only steady decrements of counts.

had to be infused after the test infusion, was also analysed comparing perfusion solutions and agents using a two sample $t$ test.

\section{Results}

The results in 21 of 23 studies were suitable for interpretation. In the solutions of mixed short chain fatty acids group, one subject who received pretreatment with morphine was removed from analysis because the right colon was considerably overlapped by the transverse colon in all scans. In the solutions of mixed short chain fatty acids/ placebo pretreatment group, the data from one subject could not be analysed because the infusion was made inadvertently into the transverse colon.

VOLUMES OF THE RIGHT COLON

Volumes (median volume for the period 31-90 minutes) of the right colon, and the effects of

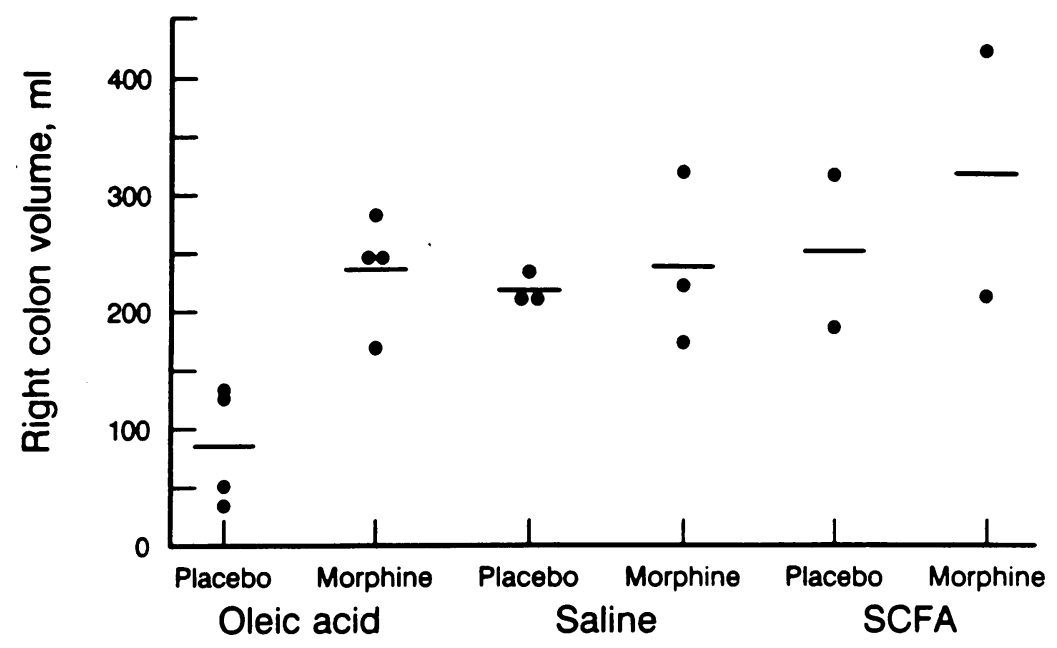

Figure 4: Mean colonic volumes (during the period 31-90 minutes of infusion) when differen solutions were infused into the caecum. Infusion groups are shown separately, by the pretreatment they received, placebo or morphine. morphine are given in Figure 4. When the oleic acid emulsion was infused and subjects received pretreatment with placebo, the right colon contained lesser volumes (mean $87 \mathrm{ml}$ ) compared to those in whom saline was infused (mean $218 \mathrm{ml}$; $\mathrm{p}<0.05$ ). Scintiscans from two persons are compared in Figure 2. No significant differences were detected between the saline and solutions of mixed short chain fatty acids treatments. The other striking effect was that of morphine pretreatment during the infusion of oleic acid (Fig 4). Treatment with the opiate increased the volume of the right colon from (a mean of) 87 to $236 \mathrm{ml}(\mathrm{p}<0.05)$. In this small number of subjects, morphine had no obvious effects on colonic volumes during saline or solutions of mixed short chain fatty acids infusions.

During saline infusion, right colonic volumes were less after naloxone treatment than after morphine or placebo (Table II), but not significantly so. Comparisons were also possible between the volume of the right colon perfused with saline at $2.5 \mathrm{ml} / \mathrm{min}$ and $8.3 \mathrm{ml} / \mathrm{min}$. During hours one and two when saline was introduced at $2.5 \mathrm{ml} / \mathrm{min}$ (pretreatment with placebo), the volume of the right colon was $218 \mathrm{ml}$ (range, 210 to $234 \mathrm{ml}$ ); in hours three and four during perfusion at $8.3 \mathrm{ml} / \mathrm{min}$, the volume was $373 \mathrm{ml}$ (245-264).

TRANSIT FROM THE RIGHT COLON

The results are summarised in Table III, as the proportionate emptying of the right colon at 90 minutes. Curves for the emptying of counts from the right colon, for the three sets of subjects, are given in Figure 3. The proportions remaining in

TABLE III Emptying of the right colon during caecal infusion of three solutions

\begin{tabular}{llll}
\hline Infusate & $n=$ & Pretreatment & $\begin{array}{l}\text { Counts remaining in the } \\
\text { right colon at } 90 \text { minutes }(\%)\end{array}$ \\
\hline Oleic acid & $(4)$ & Morphine & $71(08)$ \\
Oleic acid & $(4)$ & Placebo & $41(08)$ \\
Saline & $(3)$ & Morphine & $79(12)$ \\
Saline & $(3)$ & Placebo & $76(10)$ \\
Saline & $(3)$ & Naloxone & $60(05)$ \\
SCFA* & $(2)$ & Morphine & $96(10)$ \\
SCFA & $(2)$ & Placebo & $72(03)$
\end{tabular}

*SCFA $=$ Short chain fatty acids (acetate, propionate, butyrate)

TABLE IV Total volume ( $\mathrm{ml}$ ) accepted by human colon

\begin{tabular}{llll}
\hline Infusate & $n$ & Pretreatment & Colon capacity \\
\hline Oleic acid & (4) & Morphine & 600 \\
Oleic acid & (4) & Placebo & 286 \\
Saline & (3) & Morphine & 3499 \\
Saline & (3) & Placebo & 1514 \\
SCFA & (2) & Morphine & 3298 \\
SCFA & (2) & Placebo & 470 \\
\hline ॠ Mean values. & &
\end{tabular}

TABLE V Median percentage of total infused counts present in terminal ileum during $0-30$ minutes

\begin{tabular}{lllrrrl}
\hline Oleic/P & Oleic/M & Sal/P & Sal/M & Sal/N & SCFA/P & SCFA/M \\
\hline 0 & 3 & 0 & 3 & 9 & 15 & 15 \\
0 & 27 & 2 & 0 & 0 & 0 & 40 \\
0 & 64 & 0 & 91 & 12 & & \\
0 & 66 & & & & &
\end{tabular}
${ }^{\star}$ Infusates were: Oleic $=$ emulsion of oleic acid, $\mathrm{Sal}=154 \mathrm{mM}$
$\mathrm{NaCl}, \mathrm{SCFA}=$ mixture of short chain fatty acids. Pretreatments $\mathrm{NaCl}, \mathrm{SCFA}=$ mixture of short chain fatty acids. Pretreatment
were: $\mathrm{P}=$ placebo, $M=$ morphine, $\mathrm{N}=$ naloxone (see texts for were: $\mathrm{P}=$
details). 
TABLE VI Proportionate distribution of counts in transverse and distal colons ${ }^{\star}$

\begin{tabular}{lll}
\hline & \multicolumn{2}{l}{ Proportions of counts } \\
\cline { 2 - 3 } $\begin{array}{ll}\text { Study group } \\
\text { Perfusatelpretreatment }\end{array}$ & In transverse colon & In distal colon \\
\hline Oleic acid/placebo & 0.24 & 0.76 \\
Oleic acid/morphine & 0.43 & 0.57 \\
Saline/placebo & 0.24 & 0.71 \\
Saline/morphine & 0.24 & 0.76 \\
SCFA/placebo & 0.23 & 0.77 \\
SCFA/morphine & 0.63 & 0.37 \\
\hline
\end{tabular}

*Group means of median proportionate counts in transverse colon or distal colon (that is, descending and rectosigmoid colons), during the period that $25 \%$ or more of total counts had moved

beyond the right colon.

the right colon for subjects receiving oleic acid perfusion were higher with morphine pretreatment as compared with placebo $(p=0.05)$. In addition, the proportions of counts remaining were lower in subjects receiving oleic acid as compared with those receiving saline, when pretreatment was with placebo $(\mathrm{p}<0.05)$.

Another index of overall colonic transit was the capacity of the entire colon - that is, amounts

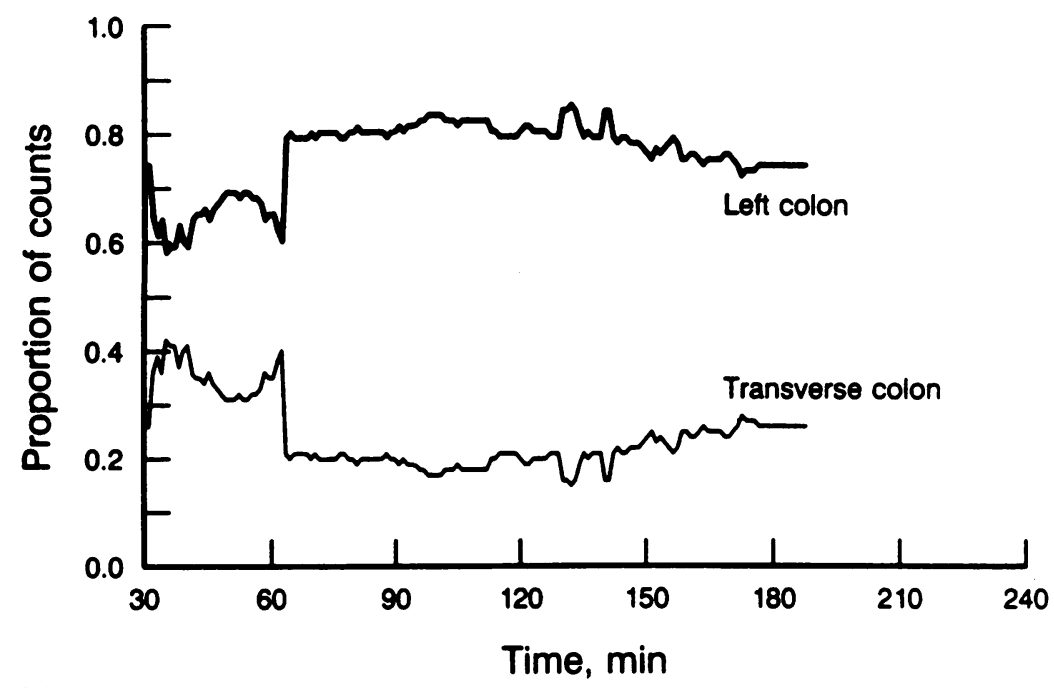

(a)

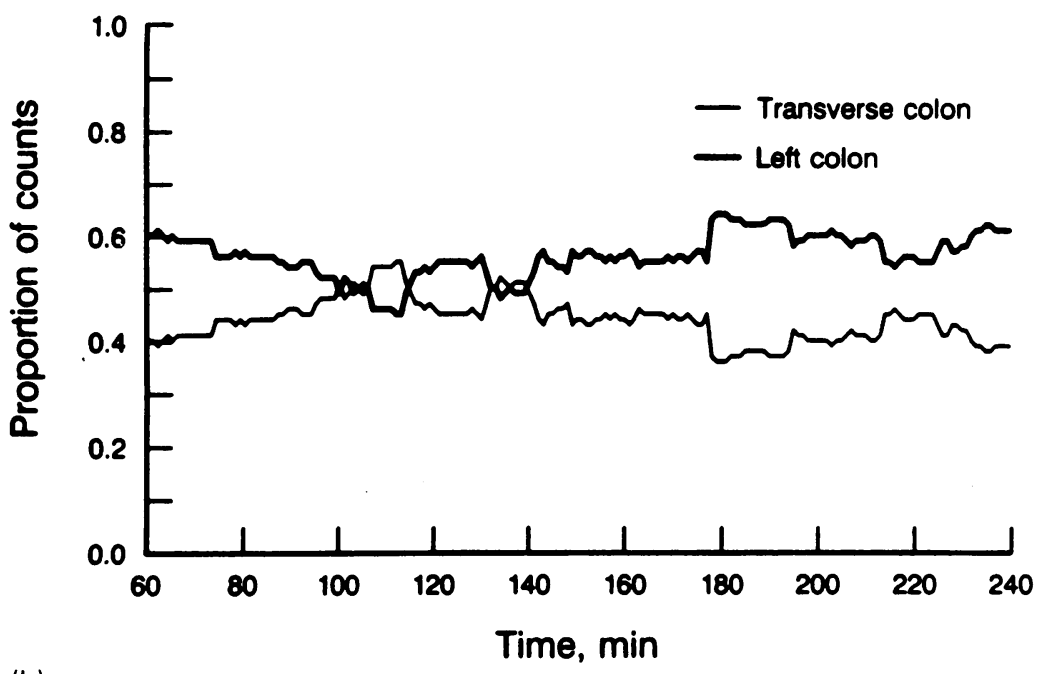

(b)

Figure 5: Proportionate counts remaining in the transverse colon and those moved into the left (descending and rectosigmoid) colon. The proportion shown is relative to all counts leaving the right colon (caecum and ascending colon). The plateaus of counts indicate that counts leaving the transverse colon approximate those entering it. (a) Values from a subject infused with oleic acid and pretreated with placebo; the proportion retained in the transverse colon 20 to $30 \%$.

(b) Values for a subject infused with oleic acid and pretreated with morphine. The proportion retained in the transverse colon was approximately $40 \%$ infused up to the time of defecation (Table IV). Analysis of $(\log )$ colonic capacity indicated significant differences between morphine and placebo for oleic acid perfusion $(p<0.05)$, and between oleic acid and saline when the pretreatment was placebo $(\mathrm{p}<0.05)$.

Percentages of total counts that refluxed into the ileum ranged from 0 to $91 \%$ (Table V); some counts refluxed in more than half the studies. Reflux was not associated with the nature of the perfusate, but was favoured by pretreatment with morphine. Thus, when the pretreatment was morphine, ileal reflux occurred in eight of nine studies; reflux occurred in only four or 12 of other studies. The morphine effect was most obvious when the infusate was oleic acid. After morphine pretreatment, reflux was prominent in four of four subjects receiving oleic acid, but reflux was not detectable when pretreatment was with placebo (Table IV).

\section{TRANSIT IN THE TRANSVERSE COLON}

Movement through the transverse colon was assessed only during the period when sufficient counts $(\geq 25 \%$ of total counts infused into the caecum) had moved beyond the right colon. Table VI shows the proportionate counts in the transverse and distal (descending and rectosigmoid) colons during these times. When oleic acid was infused, morphine increased the proportion of counts in the transverse colon (Fig 5), but a statistically significant change was not detected. Figure 5 also illustrates that the proportions of counts in the transverse colon remained fairly constant, that is, the transverse colon was behaving largely as a passive conduit. Morphine had a less constant effect on counts retained in the transverse colon when saline or solutions of mixed short chain fatty acids were the infusates.

\section{MOTILITY AND TRANSIT}

Prolonged propagated contractions were seen only when the pretreatment was placebo and the colonic infusate was oleic acid. Prolonged propagated contractions were associated with abdominal cramps, an urge to defecate and large distal movements of isotope (Fig 6). When colonic prolonged propagated contractions occurred in rapid succession the right colon was essentially emptied of fluid. No mass movements - that is, movement of $\geq 20 \%$ of colonic counts occurred in the absence of prolonged propagated contractions.

Motility indices in the jejunum were not different among the perfusing solutions, oleic acid, solutions of mixed short chain fatty acids, or saline.

\section{Discussion}

These results confirm and extend our earlier conclusion' that the proximal colon of man is able to accommodate different volumes, depending on the nature of the contents. These are, we believe, the first direct observations of capacitance phenomena in the human colon. A striking effect of an emulsion of oleic acid on colonic capitance and transit was again shown, and, as 


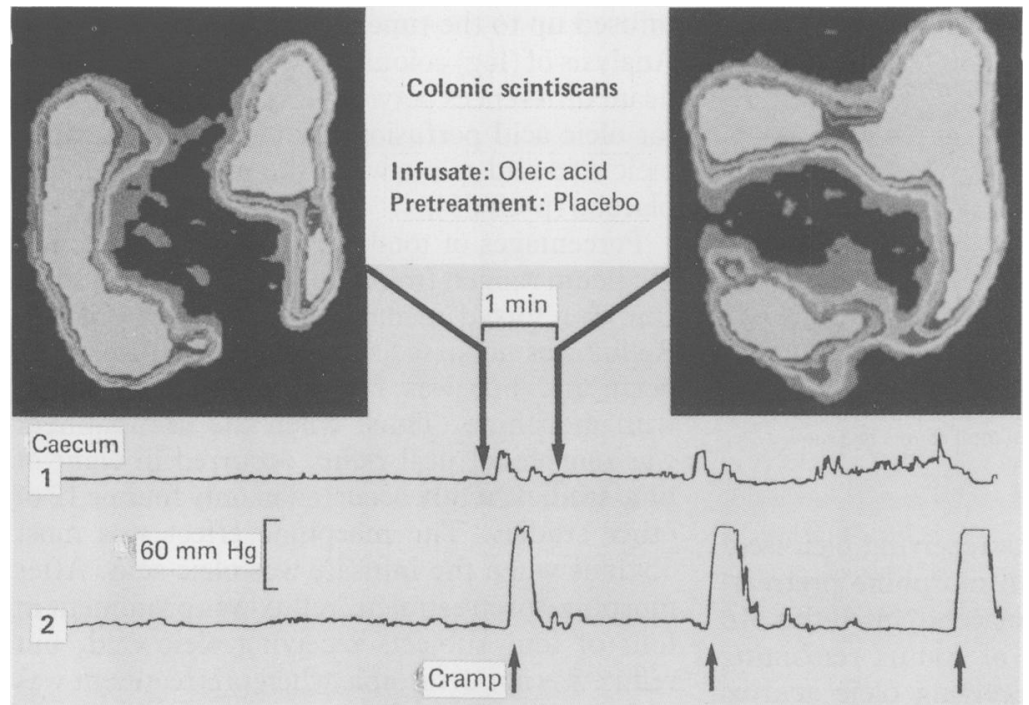

Figure 6: Scintiscan and simultaneous motility tracing from the right colon of a person who received an intracecal infusion of oleic acid (pretreatment with placebo). In an interval of one minute, a mass distal movement of isotope was noted, during which high pressure waves were recorded from the ascending colon. The subject also complained of cramping abdominal pain.

we have discussed before, ${ }^{9}$ these effects are most unlikely to be because of different rates at which fluid was absorbed or secreted under the influence of the different perfusates. Moreover, the scintigraphic methods used here to assess colonic volume were more complete than those of the earlier study. ${ }^{9}$ Scintigrams were obtained in two dimensions, anteroposterior and lateral, permitting a more confident and complete reconstruction of the proximal large bowel. Moreover, the present calculations of colonic shape and size were firmly based on phantom studies, published elsewhere. ${ }^{19}$

Certain limitations of our experiments, however, must also be recognised. These were long and uncomfortable studies for our volunteers; moreover, they were time consuming for the investigators, both in their performance and analysis. Thus, the number of persons studied in each group was small, and only one treatment could be administered to each subject. Moreover, technical failure necessitated removing two experiments from analysis in the solutions of mixed short chain fatty acids group. It is clear, therefore, that type 2 errors were certainly possible. Though the discrete power of our design cannot be evaluated, the small numbers dictate that only major trends of the data can be considered. The other problem was that subjects' tolerance to perfusion of the oleic acid was limited; discomfort and diarrhea were such that the lipid emulsion could be infused for only about 90 minutes. Together with the need to infuse the test solutions for approximately 30 minutes before the right colon could be filled reproducably, these considerations restricted our major comparative analyses to the period of 30-90 minutes of infusion.

Without pretreatment with morphine, infusion of oleic acid into the caecum resulted in a reduction to one third of the volume contained by the right colon when compared with the saline controls. These small volumes were returned to the values observed during saline perfusion after a standard therapeutic dose of morphine. On the other hand, in the small numbers we studied, morphine did not appear to increase significantly the volume contained in the proximal large bowel when the lumen contained isotonic saline or solutions of mixed short chain fatty acids. Moreover, naloxone did not significantly reduce the volume of saline contained in the right colon, even though a trend was suggested (Table II). At this point, we must provisionally conclude that opiate receptors mediate relaxation of the proximal colon but, in this small number of observations, only when the bowel was stimulated by a luminal factor (fatty acids) that restricted its capacity to accommodate.

We had also anticipated that short chain fatty acids might be accommodated even better than was saline; that is, that colonic volumes would be greater during perfusion of solutions of mixed short chain fatty acids. The results to date do not support this hypothesis. Solutions of mixed short chain fatty acids are the major anions of stool water, ${ }^{112}$ are thought to be a source of energy for colonic mucosa ${ }^{20}$ and they facilitate colonic absorption of salt and water. ${ }^{21}$ Thus, it seemed possible that they might facilitate retention of contents in the colon and, by slowing transit, augment absorption. Though the data do not support the hypothesis, our numbers are small, and the concept perhaps deserves further examination.

Our technique of constant infusion of a large volume of fluid is not 'pyhsiological'; it is perhaps most akin to the pathophysiological conditions of diarrhea, when the colon receives large volumes of fluid. Moreover, dietary measures had reduced the intake of non-absorbable residues. Yet, this was a convenient method of testing the hypothesis, by assessing maximum volumes accommodated by the proximal colon. We were then able to construct "colonic emptying curves'; however, it was difficult and perhaps inappropriate to express our data in conventional terms (such as $t^{1 / 2}$ of emptying). The bolus injection of isotope into the caecum, as used by Krevsky and his colleagues, ${ }^{22}{ }^{23}$ may have advantages in this regard. Nevertheless, there were striking effects of oleic acid and morphine on emptying from the right colon. Under our circumstances of constant infusion, we did not find that the transverse colon retained contents preferentially; this is in contrast with Krevsky's findings. ${ }^{22}$ Results from these different approaches cannot be compared directly, however; our methods do not even approximate the transit of normal contents. In our hands, the transverse colon behaved as a simple conduit, and morphine evoked only a suggestive increase of capacitance of this segment of bowel.

The reaction of the proximal colon to the fat content of patients with moderately severe steatorrhoea ${ }^{9}$ was to accelerate transit. The striking ability of morphine to reverse the effect of oleic acid suggests that an opiate receptor is involved, though the level at which this receptor acts cannot be specified. On the other hand, morphine did not appear to 'relax' the colon exposed only to saline or solutions of mixed short chain fatty acids; moreover, the failure of naloxone to influence colonic volume and transit suggests a minimal role, at best, for opiate recep- 
tors in the control of colonic capacitance under 'physiological' circumstances. Intraluminal lipid is known to exert feedback control of motility at other loci; ileal infusion of lipids alters jejunal motility and transit, by the 'ileal brake'. ${ }^{24}$ Kinsman and $\operatorname{Read}^{26}$ have also reported that the 'ileal brake' is sensitive to opiates.

The other aspect of our results worthy of comment relate to the antidiarrheal effect of opiates. Morphine is an established antidiarrhoeal agent, ${ }^{27}$ but its mode of action is uncertain. Although opiates influence ion transport across intestinal mucosa in rabbits ${ }^{28}$ studies in man suggest that a change in motor function is their predominant antidiarrhoeal action..$^{29}$ Thus, opiates are thought to increase intestinal absorption by increasing the contact time of luminal fluids with mucosal cells and not by increasing the rate of absorption. ${ }^{30}$ These effects were proposed to predominate in the small intestine, ${ }^{29}{ }^{30}$ though our experiments suggest that another major site of action of morphine is the colon. This is in contrast with earlier studies, using codeine, which showed no action of opiates on the passage of fluid through the colon. ${ }^{30}$

Morphine also appeared to facilitate caecoileal reflux, implicating yet another mechanism whereby fluid may be retained in the bowel and its passage to the rectum retarded. We were unable to show that coloileal reflux was the result of orad migration of the infusion port, though the effect on reflux of a tube passing through the ileocolonic junction is unknown. At this time it is not possible to equate the finding that morphine augmented coloileal reflux with reports that opiates increased the tone of the ileocolonic sphincter. ${ }^{31} 32$

A final observation relates to comparisons between the volume of saline accommodated by the right colon during different rates of infusion. Increasing the rate of saline infusion from 2.5 to $8.3 \mathrm{ml} \mathrm{min}$, increased the capacitance of the proximal colon by $75 \%$. Again, our numbers were small, a statistical significance was not achieved, and the sequence of different perfusion rates was not randomised. Nevertheless, the former figure $(2.5 \mathrm{ml} \mathrm{min})$ simulates ileal flow rates in health ${ }^{817}$ and the latter approximates severe diarrhoea ${ }^{18}$; thus, greater capacitance for larger volumes during diarrhoeal states might be relevant pathophysiologically.

These experiments were designed to test the hypothesis that the proximal colon of man exhibited accommodation, and that the phenomenon of relaxation was under the control of luminal receptors. The present data support this concept, though more direct experimental evidence must await application of novel methods. The luminal 'barostat', which monitors intestinal tone has been applied to the canine colon ${ }^{33}$; the proximal large bowel exhibited tonic changes and these approaches await being applied to man.
The authors wish to thank Ms A Haddad and Mr R Tucker for technical assistance, and the staff of the Mayo General Clinical Research Center for their care of the subjects. Ms L Law prepared the manuscript.

1 Cannon WB. The movements of the intestines: studies by means of the roentgen rays. Am f Physiol 1902; 6: 251-77.

2 Devroede G. Storage and propulsion along the large intestine. In: Bustos-Fernandez L, ed. The colon: Structure and func tion. New York: Plenum Medical Book Company, 1983:

3 Elliott TR, Barclay-Smith E. Antiperistalsis and other muscular activities of the colon. 7 Physiol (Lond) 1904; 31 272-304

4 Hertz AF, Newton A. The normal movements of the colon in man. F Physiol (Lond) 1913; 47: 57-65.

5 Holdstock DJ, Misiewicz JJ, Smith T, Rowlands EN. Propulsion (mass movements) in the human colon and its relationship to meals and somatic activity. Gut 1980; 11 : 91-9.

6 Ritchie J. Mass peristalsis in the human colon after contact with oxyphenisatin. Gut 1972; 13: 311-9.

7 Christensen J. Motility of the colon. In: Johnson LR, ed. Physiology of the gastrointestinal tract. New York: 1987; 665-93.

8 Debongnie JC, Phillips SF. The capacity of the human colon to absorb fluids. Gastroenterology 1978; 74: 698-703.

9 Spiller RC, Brown ML, Phillips SF. Decreased fluid tolerance, accelerated transit and abnormality of the human colon ance, accelerated transit and abnormality of the human color

10 Cummings I. Short chain fatty acids in the human colon. Gut 1981; 22: 763-79.

11 Rubinstein $R$, Howard AV, Wrong OM. In vivo dialysis of feces as a method of stool analysis IV. The organic anions component. Clin Sci 1969; 37: 549-64.

12 Kamath PS, Phillips SF, Zinsmeister AR. Short-chain fatty acids stimulate ileal motility in man. Gastroenterology 1988; 95: 1496-502.

13 Kerlin P, Tucker R, Phillips SF. Rapid intubation of the ileocolonic region of man. Aust N Z7 Med 1983; 13: 591-3.

14 Bo-Linn GW, Fordtran JS. Fecal fat concentration in patients with steatorrhea. Gastroenterology 1984; 87: 319-22.

15 Florent C, Flourie B, Leblond A, Rautureau M, Bernier JJ, Rambaud JC. Influence of chronic lactulose ingestion on the Rambaud JC. Influence of chronic lactulose ingestion on the colonic metabolism of lactulose

16 Jouany JP. Volatile fatty acid and alcohol determinations in digestive contents, silage juices, bacterial cultures, and anerobic fermentor contents. Sciences Des Aliments 1982; 2: $131-44$.

17 Phillips SF, Giller J. The contribution of the colon to electrolyte and water conservation in man. $f \mathrm{Lab}$ Clin Med 1973; 81: 733-46.

18 Banwell JC, Pierce NF, Mitza RC, et al. Intestinal fluid and electrolyte transport in human cholera. $\mathcal{f}$ Clin Invest 1970; 49: 183-95.

19 O'Connor MK, Oswald W, Kamath PS, Phillips SF. The use of profile analysis for the assessment of organ dimensions. Eur $\mathcal{F}$ Nucl Med 1988; 14: 562-4.

20 Roediger HEW. Utilization of nutrients by isolated epithelial cells of the rat colon. Gastroenterology 1982; 83: 424-9.

21 Ruppin H, Bar-Meir S, Soergel LH, Wood CM, Schmitt MG. Absorption of short chain fatty acids by the colon. Gastroenterology 1980; 78: 1500-7.

22 Krevsky B, Malmud LS, D'ercole F, Fisher RS. Colonic transit scintigraphy. A physiologic approach to the measurement of colonic transit in humans. Gastroenterology 1986; 91 : 1102-12.

23 Kaufman PH, Krevsky B, Malmud LS, Maurer AH, Somers MB, Siegel JA, Fisher RS. Role of opiate receptors in the regulation of colonic transit. Gastroenterology 1988; 94: 1351-6.

24 Read NW, McFarlane A, Kinsman RI, et al. Effect of infusion of nutrient solutions into the ileum on gastrointestinal transit of nutrient solutions into the ileum on gastrointestinal transit
and plasma levels of neurotensin and enteroglucagon. and plasma levels of neurotensin.

25 Spiller RC, Trotman IF, Higgins B, et al. The ileal brake inhibition of jejunal motility after ileal fat infusion in man. Gut 1984; 25: 365-74.

26 Kinsman RI, Read NW. Effect of naloxone on feedback regulation of small bowel transit by fat. Gastroenterology 1984; 87: 335-7.

27 Burks TF. Gastrointestinal pharmacology. Annu Rev Phar macol Toxicol 1976; 16: 15-31.

28 McKay JS, Linaker BD, Turnberg LA. Influence of opiates on ion transport across rabbit ileal mucosa. Gastroenterolog $1981 ; 80: 279-84$.

29 Schiller LR, SantaAna CA, Morawski SA, Fordtran JS Mechanism of the anti-diarrheal effect of loperamide. Mastroenterology 1984; 86: 1475-80.

30 Schiller LR, Davis GR, SantaAna CA, Morawski SA, Fordtran JS. Studies on the mechanism of the anti-diarrheal tran JS. Studies on the mechanism of the anti-dia

31 Ouyang A, Clain CJ, Snape WJ, Cohen S. Characterization of opiate mediated responses of the feline ileum and ileo-ceal opiate mediated responses of the feline il

32 Borody JJ, Quigley EMM, Phillips SF, et al. Effects of morphine and atrophine on motility and transit in the human ileum. Gastroenterology 1985; 89: 562-70.

33 Neri M, Phillips SF, Fich A. Measurement of tone in the proximal canine colon [Abstract]. Gastroenterology 1989; 96 : A364. 